\title{
REFERENCE RANGES OF URINARY LEVELS OF KIM-1 AND IL-18 IN TERM AND PRETERM NEWBORNS IN THEIR FIRST 48 HRS OF LIFE
}

\author{
T ${ }^{1}$ Anna Tarko, ${ }^{1}$ Anna Suchojad, ${ }^{2}$ Anna Jarosz-Lesz, ${ }^{3}$ Barbara Przybył, ${ }^{1}$ Iwona Maruniak-Chudek \\ Silesia, Katowice, Poland; ${ }^{2}$ Neonatology Unit, Guardian Angels Hospital of the Brothers Hospitallers of \\ St. John of God in Katowice, Poland; ${ }^{3}$ Clinical Unit of Neonatology and Intensive Care, Multidisciplinary \\ Hospital E. Warmiński, Bydgoszcz, Poland
}

\section{BACKGROUND AND AIMS}

KIM-1 and IL-18 measured in urine have been described as potential markers of acute kidney injury, but their role as inflammatory indicators were also raised. Their values were seldom measured in healthy population to establish reference values.

\section{METHODS}

We evaluated both substances in urine samples collected from 80 healthy term newborns and 70 preterm infants on their first 48 hours of life. All the patients were managed routinely and did not underwent any intensive medical interventions.

\section{RESULTS}

Mean gestational age (GA) and birth weight (BW) were: 39 wks (range: $37-41), 3414$ grams (range: 3324-3502) and 34 wks (range: 31-36), 2229 grams (range: 2089-2369), in term and preterm newborns, respectively. In term newborns, $10^{\text {th }}$ and $90^{\text {th }}$ centiles of KIM-1 values were 0.21 and $2.27 \mathrm{ng} / \mathrm{ml}$ (median 0.66), and for IL-18: 5.4 and $81.5 \mathrm{pg} / \mathrm{ml}$ (median 20.2), respectively. In preterm newborns, median values of $\mathrm{KIM}-1$ was $0.45 \mathrm{ng} / \mathrm{ml}\left(10^{\text {th }}-90^{\text {th }}\right.$ centile: 0.09 and 2.30), while for IL-18: $62 \mathrm{pg} / \mathrm{ml}$ (10 ${ }^{\text {th }}-90^{\text {th }}$ centile: 31.3 and 569$)$. In the whole study populations KIM-1 correlated with $\mathrm{GA}(\mathrm{R}=0.170$, $\mathrm{p}=0.04)$ and BW $(\mathrm{R}=0.202, \mathrm{p}=0.01)$, while $\mathrm{IL}-18$ correlated with GA $(R=-0.493, p<0.001)$, BW $(R=-$ 0.436, $p<0.001)$ and Apgar 5' $(R=-0.358, p<0.001)$. They both were not influenced by stress factors noted during pregnancy or at delivery. Nasal CPAP introduced to the preterm newborns also did not affect KIM-1 or IL-18 concentrations.

\section{CONCLUSIONS}

Term, healthy newborns presented slightly higher values of $\mathrm{KIM}-1$ and lower IL-18 in comparison to preterm newborns, born in good clinical condition, with no or only mild respiratory insufficiency. Values of studied markers were quite stable in both populations and were influenced by basic demographic, but not by clinical parameters.
Table 1. Demographic factors and clinical parameters of the study population, presented separately for term and preterm newborn. *- median

\begin{tabular}{|c|c|c|c|}
\hline & $\begin{array}{l}\text { PRETERM } \\
\text { [N=70] }\end{array}$ & $\begin{array}{l}\text { TERM } \\
{[\mathrm{N}=80]}\end{array}$ & $\begin{array}{l}\text { Statistical } \\
\text { significance }\end{array}$ \\
\hline Gender (M/F) & $42 / 28$ & $48 / 32$ & $P=0.87$ \\
\hline Gestational age (wks) ${ }^{*}$ & 34 [33-36] & 39 [38-40] & $P<0.001$ \\
\hline Birth weight (g) & $\begin{array}{c}2229 \\
{[2089-2369]}\end{array}$ & $\begin{array}{c}3414 \\
{[3324-3502]}\end{array}$ & $P<0.001$ \\
\hline Apgar $5^{\prime}(p t s)^{*}$ & 9 [8-10] & $10[10-10]$ & $P<0.001$ \\
\hline $\mathrm{KIM}-1(\mathrm{ng} / \mathrm{ml})^{*}$ & $\begin{array}{c}0.45 \\
{[0.19-0.98]}\end{array}$ & $\begin{array}{c}0.66 \\
{[0.33-1.07]}\end{array}$ & $P=0.36$ \\
\hline IL-18 (pg/ml) $)^{*}$ & $62[41-114]$ & $20[11-36]$ & $P<0.001$ \\
\hline $\begin{array}{l}\text { Stress factors in } \\
\text { pregnancy }(Y / N)\end{array}$ & $30 / 40$ & $9 / 71$ & $P<0.001$ \\
\hline $\begin{array}{l}\text { Stress factors during } \\
\text { delivery }(Y / N)\end{array}$ & $29 / 41$ & $6 / 74$ & $P<0.001$ \\
\hline nCPAP (Y/N) & $38 / 32$ & $0 / 80$ & $P<0.001$ \\
\hline
\end{tabular}

Fig. 1 Comparison of IL-18 values between term and preterm newborns

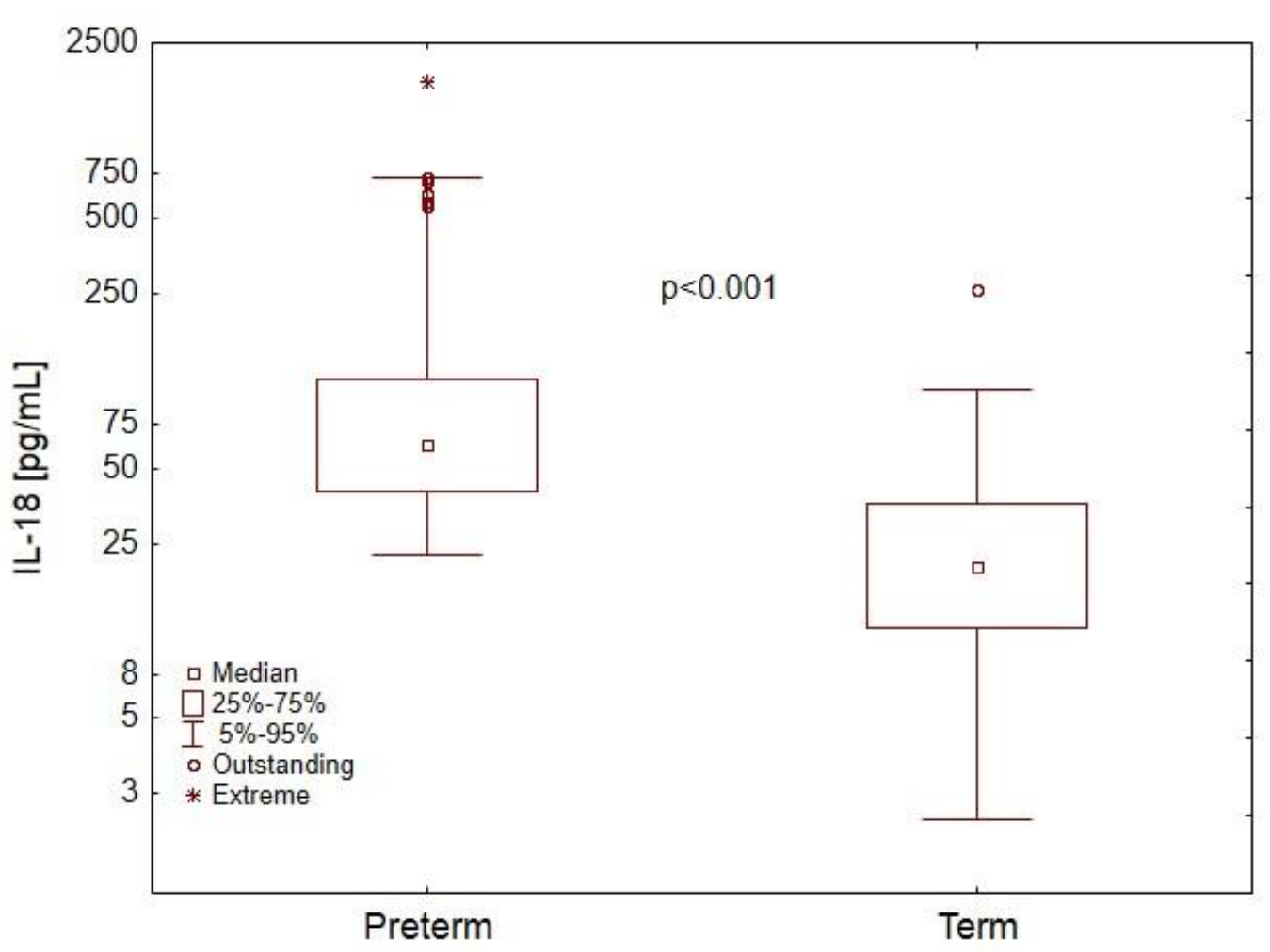

Fig. 2 Correlation between IL-18 concentration and birth weight

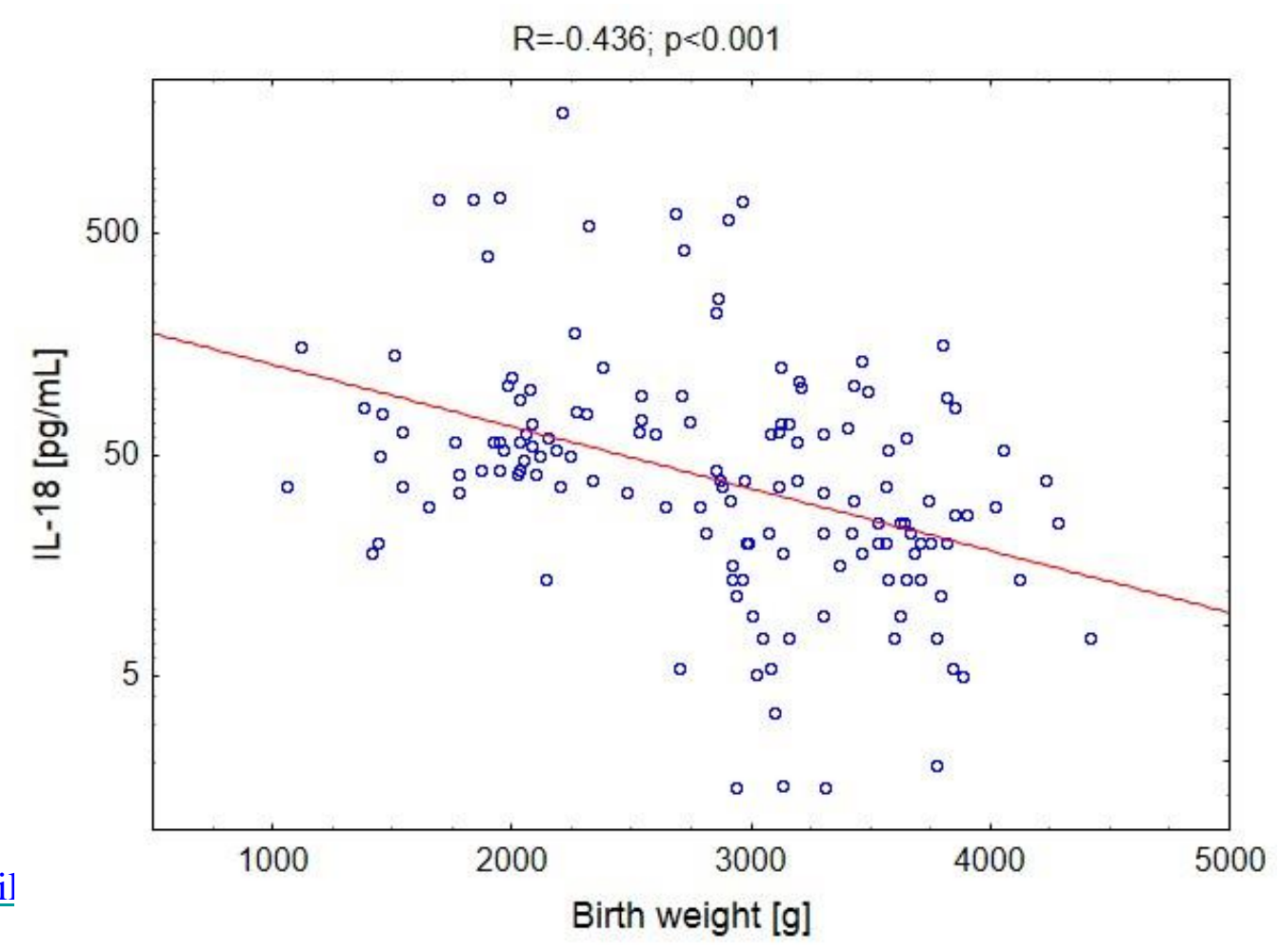

